\title{
O NEGRO NOS PRIMÓRDIOS DO CINEMA BRASILEIRO: UMA ABORDAGEM ENTRE A LITERATURA E A IMPRENSA
}

Lucinéia Alves dos SANTOS

Universidade Federal do Amapá (UNIFAP)

lucineiaalves@unifap.br

Resumo: Abordaremos neste trabalho três linguagens diversas: literatura, imprensa e cinema. Embora essas linguagens sejam diferentes, sofrem influências entre si no final do século XIX e início do século $X X$, momento em que surge o cinematógrafo. Para demonstrar tais influências neste período, abordaremos duas personalidades negras que tiveram papel importante para a consolidação do cinematógrafo brasileiro $e$ ao mesmo tempo se destacaram na literatura ou na imprensa nacional: João do Rio e Benjamim de Oliveira.

Palavras-chave: Literatura. Cinema. João do Rio. Benjamim de Oliveira.

\begin{abstract}
This essay will approach three language manifestations: Literature, Printing Press and Cinema. Although these languages are diverse, they influenced one another at the end of the $X I X$ (nineteenth) and beginning of the XX (twentieth) centuries, that is, at the moment cinematographer has one come out. To demonstrate such impulses in this period we will point out two black personalities who performed important roles to the consolidation of Brazilian Cinematographer and stood out from Literature or in national Printing Press as well: João do Rio and Benjamim de Oliveira.
\end{abstract}

Keywords: Literature. Cinema. João do Rio. Benjamim de Oliveira 


\section{Introdução}

Neste trabalho abordaremos duas personalidades negras que participaram da consolidação do cinematógrafo brasileiro, atuando ou escrevendo sobre este evento. Faremos um recorte dos anos de 1907 a 1910, período de grande produção nos trabalhos do literato e artista analisados em concomitância com o auge da cinematografia brasileira, estes homens são João do Rio e Benjamim de Oliveira, ambos percorreram três manifestações diversas: cinema, imprensa e literatura. João do Rio trilhou o caminho da imprensa como jornalista, literatura por ser cronista, e cinema por abordar o tema em sua literatura e mostrar a visão que possuía do cinematógrafo. Já Benjamim de Oliveira encontra-se no âmbito cinema/imprensa, embora tenha sido importante também para o circo e o disco, como veremos em um capítulo específico.

O momento analisado estava à frente da abolição da escravatura apenas 20 anos. Agravando assim a visão apresentada nos estudos de teorias raciais, onde acreditava-se que as pessoas negras, indígenas e mestiças eram o atraso da nação brasileira. Entretanto, nossos protagonistas contribuíram para o desenvolvimento da nova arte que surgia e deixaram seus registros na história como veremos.

\section{João do Rio e a experiência de seu tempo}

João Paulo Alberto Coelho Barreto (João do Rio) foi um literato importante e grande jornalista, nasceu no Rio de Janeiro em 1881. Era mulato, a mãe era de origem negra e o pai branco. Sua avó materna era mestiça e chamava-se Gabriela Amália Caldeira, fora amásia de um homem branco e médico chamado Joaquim Cristóvão. Este não contraiu matrimônio com Gabriela, pois ela era "quase negra e analfabeta". Porém juntos tiveram quatro filhas. O doutor Joaquim Cristóvão deixou a amásia negra para casar-se com uma mulher branca da alta-sociedade. Esta era a ascendência de João do Rio que às vezes era atacado por sua origem.

Mesmo sendo de descendência afro-brasileira, João do Rio parecia não se considerar negro, esse dado é perceptível pelas imagens existentes do escritor, como a 
fotografia oficial para a Academia de Letras, que foi retocada principalmente na região do nariz.

Naquele momento era muito comum este processo de retocar fotografias por questões raciais. As pessoas usavam pó de arroz na face para ficarem mais claras. No início do século XX, estava em voga o 'darwinismo racial', acreditava-se que em um século a população negra desapareceria do território brasileiro através da mestiçagem, desta maneira o país teria um grande progresso. Lilian Schwarcz aborda o tema em seu livro O espetáculo das raças, onde cita como exemplo deste ideal de embranquecimento o quadro A Redenção de Cam, que apresenta a imagem de uma mulher negra de mãos aos céus como se estivesse dando graças, uma jovem mulher mulata com uma criança de aparência branca ao colo, e o pai branco, porém de fisionomia mestiça, observando sorridente a criança. Este quadro foi reproduzido em um ensaio datado de 1911, que abordava o branqueamento brasileiro. Sob a reprodução havia esta frase: "Le nègre passant au blanc, à la troisième génération, par l'effet du croisement des races." (IN: SCHWARCZ, 1993:11)

\section{O cronista e o cinematógrafo}

João do Rio presenciou o auge do cinematógrafo no Brasil, participou ativamente do evento, escrevendo um livro de crônicas intitulado Cinematographo, além de possuir uma sessão dominical na Gazeta de Notícias, com o mesmo nome.

A coluna dominical era apresentada na primeira página do jornal Gazeta de Notícias, sempre acompanhada por uma imagem, geralmente uma pintura acadêmica. O texto apresenta-se dividido em tópicos com o nome dos dias da semana e João do Rio abordava diferentes assuntos: literatura, sociedade, costumes, crítica teatral, políticos, artistas, etc. Além, é claro, do próprio objeto que nominava a coluna: o cinematógrafo. Neste trabalho, João do Rio assinava como Joe. Sob este pseudônimo, o cronista produziu o Cinematógrafo por três anos, de 1907 a 1910.

Destacaremos alguns de seus textos apresentados na crônica dominical, como a do dia 01/09/1907, com o tópico: Terça. O assunto abordado foi a vida de jornalista. Joe escreveu claramente que os jornalistas ganhavam mal e deviam vestir-se bem. Eram maltratados aonde chegavam, nem mesmo dormindo para ter um furo de reportagem: 
E vão. Não dormiram a noite passada. O jornal precisa trazer todo dia seu escandalo. O publico 'blasé' exige um assassinato diario do Carlito da Saude ou a descoberta de uma quadrilha de moedeiros falsos. (JOE, 01.09. 1907, p. 1)

Neste artigo, nosso cronista, além de abordar a vida dura dos jornalistas, mostrou a preferência dos leitores pelos fatos sensacionalistas, como assassinatos, roubos, atropelamentos por bondes, etc., enquanto a crônica mais elaborada não suscitava muito interesse.

Joe apresentou inúmeras situações em suas crônicas, como o comportamento da burguesia carioca. No dia 29/09/1907, o autor escreve sobre o Teatro Lírico: “Uf_Acabou o Lyrico_Sim_Acabou_(...)"(Idem, 29-09-1907, p.1)

A crônica Cinematógrafo de subtítulo Domingo começa com tom de comemoração pelo fim do Teatro Lírico. Joe explica que a frequência àquele lugar era modismo. As pessoas pouco prestavam atenção nas peças, mas sim na vida alheia. Nem sempre se cumprimentavam, porém sabiam tudo da vida do vizinho de camarote: o valor da hipoteca, das contas da modista... Falava-se da mulher do próximo, se estava mais envelhecida ou mais bonita. Segundo o cronista, ainda todos os frequentadores do teatro, depois de visitálo, iam ao mesmo lugar: tomar chocolate no Bravo, era a moda.

No dia 12 de abril de 1908, João do Rio escreveu em seu texto de subtítulo Sábado, sobre a moda de se falar da Europa. O cronista usa como cenário um salão elegante do Rio:

Falla-se do estrangeiro, da Europa, de Paris, das modas proximas de Longchamp, do rei Eduardo que está menos pançudo. Estaremos nós mesmo no Rio?

- Você ainda não foi á Europa?

(...)

- Mas é impossível_Va quanto antes. Você esta comettendo um crime É um meio 'snob', desse snobismo que os perderia se fosse possível (...) (Idem, 12.4.1908, p.1)

Esta mesma reflexão foi feita no dia 15 de setembro de 1907, em um artigo de subtítulo Terça, o qual há uma observação sobre conferências literárias. Ele escreve que as conferências viraram mania, mesmo se o conferencista não fosse bom, as pessoas iam prestigiá-lo só por seu nome. 
Joe destacou um destes eventos que aconteceu na Associação dos Empregados no Comércio, feito pelo francês A. De Doumer. O tema era sobre economia europeia, detalhe, a conferência foi apresentada em língua francesa. O narrador levantou uma questão: será que todos os presentes sabiam francês, já que prestavam tanta atenção e lotaram o local?

Nós somos de uma assimilação furiosa. Mas aprender francez, degerir um discurso de uma hora sobre a economia européa logo depois pareceria de mais, se quizessemos imaginar o Rio de Janeiro sem fallar francez.

Felizmente toda a gente falla francez, é francez desde o Selimidt cabellereiro até os cardapios dos hoteis.

É por isso talvez é que cada vez se sabe menos portuguez... (Idem, 19.09. 1907, p.1)

Aqui é perceptível uma grande crítica em relação à mania daquela época de “europeizar" tudo, inclusive a língua. Assim, João do Rio aponta também os erros de português apresentados na imprensa.

Além da crítica à sociedade, pontuava políticos e artistas da época. Todavia tecia elogios também, como fez ao artista Catulo da Paixão Cearense. Escreveu em seu Cinematógrafo uma crônica cheia de louvores:

Eu hoje passei um dia integralmente antigo. Esse goso é dado a todos os mortaes. Levei o tempo de dia a ler a collectanea de modinhas que o nosso assombroso Catullo da Paixão Cearense edita agora pela decima vez. Catullo é um desses casos litterarios dignos da maior attenção. Grande sacerdote da Modinha porque assim resolveu ser, conhecedor de varios versos de poetas conhecidos... (Idem. 17.05.1908, p.1)

Já no dia 13/09/1908 aborda uma personalidade da época, sem encômios. O citado é Pascoal Segreto. Joe refere-se à grande exposição em comemoração ao centenário de abertura de portos brasileiros por D. João VI. Pascoal Segreto havia contratado com os responsáveis da exposição várias diversões no local e, desta forma, tornou-se responsável pelo registro dos acontecimentos. Não queria permitir que outros filmassem o interior da Exposição, somente ele. Porém Segreto perdeu a causa e todos os interessados puderam filmar as festividades:

Esse Segreto quer abarcar o mundo com as pernas e não entende da metade das cousas que dirige- Ah! A má vontade - Pois se é o facto...? Não acredita voce que se ganharia aqui um dinheiro. (Idem. 13.09.1908, p. 1) 
O cinematógrafo é uma constante na obra de João do Rio, como podemos verificar em seus escritos, como a crônica publicada em 29.09.1907, com os subtítulos Terça e Sábado. No primeiro Joe escreve sobre crianças exploradas por adultos, sobretudo aquelas que ficam nas ruas pedindo esmolas. O narrador explica que estas crianças e adolescentes estão sujeitos ao vício, à ladroagem, à prostituição. Desta maneira, narra um episódio que presenciou, onde um menino de 6 anos estava na rua bebendo parati com groselha. $\mathrm{O}$ narrador dirigiu-se ao menor para tentar persuadi-lo a não continuar o ato, então o pequeno vira o copo de uma só vez e pergunta:

- Não vens ao 'treme-treme'?

- Que é 'treme-treme'?

- Ai coitado_Sou eu que bebi e elle é que ficou tonto

E deitou a correr para o cinematographo (...) (Idem. 29.09 .1907$, p.1)

O que podemos analisar nesta crônica é que o cinematógrafo imperava em todas as classes sociais: até um menino que pede esmola na rua, se embriaga... vai ao cinema. Neste texto, Joe denuncia um gravíssimo problema social, mas também aponta o sucesso cinematográfico.

Ainda na mesma crônica, porém subtitulada Sábado, o narrador relata a febre dos cinematógrafos. Diz que o carioca é especialista em manias de prazer e divertimento, porém logo cansa e deixa a novidade. No entanto, com o cinematógrafo ocorre outro sintoma:

Cinematographos... Agora são os cinematographos, anuncios, ajuntando milhares e milhares de pessoas. Na avenida Central, com entrada paga ha dous tres, e a concorrencia é tão grande que a policia dirige a entrada e fica a gente esperando um tempo infinito na calçada.

Encontro (...) o meu velho amigo barão Belfort e logo este me diz:

- Ha sete pecados capitaes, sete maravilhas do mundo, as sete idades do homem, houve os sete sabios (...)

- Mas a que vem isso?

- O Rio tem agora sete prazeres tambem (...)

- E são?

- O bicho, o maxixe, o 'Vissi d'Arte', os meetings, a oposição a policia, a propaganda 'A Europa curva-se ante o Brasil' -E...? 
- E os cinematographos. (Idem, Ibidem)

João do Rio com sua percepção registrou fatos do cinematógrafo, evidenciando acontecimentos que giravam em torno deste invento que modificaria o comportamento de toda uma sociedade. $\mathrm{O}$ escritor nos mostrou como era a sociedade contemporânea a ele e a influência que o cinematógrafo trouxe às pessoas. A forma de seu registro é inspirada no cinema e as divisões apresentadas na coluna dominical Cinematógrafo nos deixa claro isso. A coluna não é um artigo somente, é um texto dividido em várias partes, tal qual, as fitas do cinema, divididas em quadros.

\section{Benjamim de Oliveira, um artista entre as várias linguagens}

Benjamim de Oliveira nasceu em Pará de Minas, em 1870. Era filho de escravos, mas era alforriado, no entanto passava por privações na fazenda onde morava. Em um período da infância, o menino negro vendia broas feitas por sua mãe aos artistas do circo que se encontrava em sua cidade. Acabou sendo atraído pelo mundo dos espetáculos, e assim fugiu com a trupe circense. No ano de 1889, Benjamim tornou-se palhaço, instrumentista e cantor na companhia circense de Fructuoso e Albano. Porém as divulgações na imprensa sobre seu trabalho aumentaram a partir do final de 1901, quando já havia desenvolvido produções de circo-teatro.

$\mathrm{O}$ artista negro consta como autor, adaptador ou parodiador em pelo menos 19 peças variadas, como farsas fantásticas, dramáticas, peças de costumes, melodramas policiais, etc... Benjamim foi responsável pelo desenvolvimento do circo-teatro, dado este que podemos confirmar através de um artigo do jornal Gazeta de Notícias, no qual o jornalista diz obter informações do artista Benjamim de Oliveira. Segue sua reportagem a respeito do desenvolvimento do teatro no circo:

Entretanto, o Sr. Spinelli logo se presta a nos deixar photographar os seus artistas; Benjamim de Oliveira, o palhaço popular, dá-nos informações, e começa o nosso Kodack a funccionar (...)" (Gazeta de Notícias, 01.09.1907, p.2) 
As informações fornecidas pelo artista serão de como se popularizou o circo no Brasil. Segundo o artigo, Benjamim relata que poucos anos após a Independência chegou a primeira companhia de burlantins em nosso país, vinda dos Estados Unidos. Depois o artigo continua com a citação de alguns números apresentados na antiga estrutura circense. Fala-se do nascimento das pantomimas que ocorreu a partir da inspiração de um empresário no século XIX, em antigos personagens das comédias clássicas italianas. Este empresário resolveu apresentar as encenações como número de atração:

Foi assim que nasceu a pantomima.

As pantomimas, que a princípio arrancaram muitas gargalhadas ao mais sisudo dos mortais, terminaram por ser enfadonhas (...) porque perderam o encanto de novidade para agradar o publico (...)

Então appareceram as farças representadas nos circos (...) (Idem, ibidem)

O mesmo artigo segue mostrando como eram feitas as peças: havia o diálogo improvisado e ensaiado pela manhã, para ser representado à noite. Por volta do fim do ano de 1901 e início de 1902, Benjamim de Oliveira começou a ensaiar as pantomimas com os colegas de circo:

Há cerca de cinco annos foi o clown Benjamim de Oliveira que assentou as bases da farça moderna, distribuindo as personagens de accordo com o physico dos artistas e ensaiando-os apuradamente. (Idem. Ibidem)

Como vimos, Benjamim de Oliveira ampliou a modalidade, que até então estava enfraquecida no meio circense, o teatro no picadeiro. Retornemos ao ano de 1901, o palhaço Benjamim era um artista de grande sucesso, era praticamente a principal atração do Circo Spinelli. Em uma estratégia de divulgação deste circo em São Paulo, foi publicada na coluna Palcos e Circos do jornal O Estado de São Paulo, a informação de que o 'aplaudido clown Benjamim de Oliveira' havia enviado um 'cartão de cumprimentos' ao jornal. Passados alguns dias da divulgação, foi publicada no mesmo jornal a propaganda do circo com a fotografia de Benjamim de smoking e com medalhas em seu peito.

Esse destaque do palhaço negro aparecerá várias vezes, como no jornal Gazeta de Notícias, que em 1907 publicou um artigo intitulado:

\section{A VIDA DOS CIRCOS}




\section{NO CIRCO SPINELLI}

O prazer do povo- Na occasião do ensaio- A evolução do circo- As pantomimas- Benjamim de Oliveira- Os progressos materiaes dos circos (Gazeta de Notícias, 01.09.1907. p. 2)

No título destacavam-se os assuntos que seriam abordados no texto, dentre os quais está o artista Benjamim de Oliveira, o único com o nome divulgado. Também o único artista, com exceção do dono do circo, a ter uma fotografia individual publicada naquele jornal. Os outros artistas foram fotografados em duplas ou em grupos.

A ascensão de Benjamim de Oliveira era evidenciada também pela forma como os jornais referiam-se a ele, não era o palhaço e sim o "clown brasileiro", pois clown, segundo os padrões europeus, é vestido e pintado de forma mais elegante. (cf. SILVA, 2003: 182)

\section{Benjamim e o cinema brasileiro}

No final do ano de 1902 estreia a pantomima Os Guaranis, baseada no romance $O$ Guarani de José de Alencar. Esta pantomima é considerada a primeira do gênero, pois até então, ninguém havia encenado um romance brasileiro em um picadeiro de circo. Apresentava música e arranjo do maestro João Santos, a mise-en scène era cuidada por Benjamim de Oliveira e o clown Cruzet. No elenco estavam Ignez Cruzet, de origem argentina, que interpretava Ceci, Benjamim de Oliveira como Peri, o clown Cruzet como Cacique, entre outros vários artistas. No Comércio de São Paulo de outubro de 1902 foi divulgado que esta pantomima tinha 22 quadros, 70 pessoas em cena, 22 números de música...

Foram publicados comentários sobre Os Guaranis em março de 1903, no Estado de São Paulo, com muitos elogios à encenação. Este trabalho foi muito marcante para o circoteatro e será também para o cinema. A pantomima foi apresentada até 1910, sempre com Benjamim interpretando Peri, e os demais personagens sendo interpretados por artistas que variavam ao longo dos anos. Em 1908, o cineasta português Antonio Leal resolveu filmar a pantomima: 
Antonio Leal filmou, com câmara imóvel, no Circo Spinelli, uma pantomima, tal qual era representada no picadeiro. Tratava-se de Os Guaranis, peça do palhaço negro Benjamim de Oliveira, inspirada no popular romance de José de Alencar. Quem fazia o papel de Peri era o próprio Benjamim (...) (ARAÚJO, 1976: 264)

Com esta filmagem, Benjamim tornou-se o precursor de uma nova modalidade, pois foi responsável pela adaptação do romance para a pantomima, possibilitando "que esse experimento fizesse parte da nascente indústria do cinema. Duas linguagens que se cruzavam, mantendo suas especificidades (...)”( SILVA, 2003: 236)

Este filme, infelizmente desaparecido, fez parte da construção da linguagem do cinema industrial brasileiro, sendo exibido pela primeira vez em 14 de setembro de 1908, no Palace: "O Cinema- Palace muda hoje de programma, exibindo duas fitas nacionais interessantissimas: Sô Loterio e Sinhá Eusebia e os Guaranys, farça pelos artistas do circo Spinelli." (Gazeta de Notícias, 14.09.1908)

Antes mesmo da filmagem da pantomima, Benjamim de Oliveira já era um artista consagrado e versátil: cantor, compositor, ator, diretor, palhaço. Este artista era visto como uma grande expressão cultural no circo:"Benjamim de Oliveira revolucionou o circo com as suas criações fantásticas de mágicas, e de operetas com diálogos, músicas e apoteoses (...)" (Gazeta de Notícias, 12.06.1907, Apud SILVA, 2003:234)

Todavia esta visão não ficou somente no circo. A sua consagração foi para o cinema e para a indústria discográfica. Benjamim foi um dos primeiros artistas a gravar discos, gravando seis no intervalo entre 1907 a 1912, com as canções Baiano na Rocha, em parceria com Mário Pinheiro, Caipira Mineiro, As Comparações, Tutu, Se fores ao Porto e A mulata Carioca.

Benjamim com seu trabalho, fez Artur Azevedo se redimir das críticas anteriores ao teatro-circo. Em 1907, Azevedo começou a expressar opinião diferente em relação ao circo, sem a visão negativa de outrora. Sua crônica publicada em 23 de fevereiro de 1907, chamava o povo para ir até o circo Spinelli e prestigiar a Pantomima Os Guaranis, e escreveu sobre o artista negro:

Pery é o Benjamim. Este nome é do mais popular dos artistas do circo Spinelli. 
É um negro, mas um negro apolíneo, plástico; um negro que, metido nas suas bombachas de 'clown', me pareceu Otelo, que saltasse das páginas de Shakespeare para um circo, na Cidade Nova. Ele não é só um saltador admirável, um emérito tocador de violão, um artista que faz da cara o que quer, parecendo ora um europeu louro como as espigas do Egito, ora o índio vermelho apaixonado pela filha de D. Antonio de Maris (...) (O Paiz, 23.02.1907, Apud. SILVA, 2003:228)

Não só no artigo de Artur Azevedo, mas também em outros apresentados neste trabalho, vimos que a genialidade de Benjamim de Oliveira era prestigiada por todos, pela imprensa e pelo seu 'respeitável público' que lotava o circo onde o artista trabalhava, bem como o Cine- Palace para assistir à fita de sua pantomima.

\section{Conclusão}

Há ainda outros negros que foram registrados nesta invenção que nascia no final do século XIX, como o navegante negro, João Cândido que comandou a Revolta da Chibata. Foram feitas várias imagens do episódio, sendo produzidas fitas como: A Revolta da Esquadra, que terminava com uma fotografia de tamanho natural de seu líder. A Revolta dos Marinheiros, Rebelião da Marinhagem da Esquadra e o documentário Gaumont Atualidades. Lembremos também de José do Patrocínio Filho que contribuiu com o cinematógrafo gerando um novo gênero de filme: a revista, com temas políticos.

Apesar das teorias racistas em voga no final do século XIX e início do século XX, negros contribuíram na literatura influenciada pelo cinematógrafo, como João do Rio. Negros tiveram participação na industrialização do cinema brasileiro, como o palhaço, cantor, ator, compositor Benjamim de Oliveira, que foi além, contribuindo com o circoteatro, novas formas de pantomimas e ainda com a discografia brasileira, gravando vários discos no início do século XX, quando nascia esta nova forma de registrar canções.

\section{Referências}


ARAÙjO, Vicente de Paula. A Bela Época do Cinema Brasileiro. São Paulo: Perspectivas (Debates), 1976.

RODRIGUES, João Carlos. João do Rio: Uma Biografia. Rio de Janeiro: Topbooks, 1996. . O Negro Brasileiro e o Cinema. Rio de Janeiro: Pallas, 2001.

SCHWARCZ, Lilia Moritz. O espetáculo das Raças: Cientistas, Instituições e questão racial no Brasil 1870-1930. São Paulo: Companhia das Letras, 1993.

SILVA, Erminia. As múltiplas Linguagens na Teatralidade Circense. Benjamim de Oliveira e o circo-teatro no Brasil no final do século XIX e início do XX. Campinas, SP: Universidade Estadual de Campinas, Instituto de Filosofia e Ciências Humanas. Tese de Doutorado, 2003.

\section{Periódicos}

CARETA, Rio de Janeiro. 30 abril 1910, apud ARAÚJO, 1976.

Gazeta de Notícias, Rio de Janeiro, p.02. 01 set. 1907; 12 set. 1908; 14 set. 1908; 15 set. 1908.

Gazeta de Notícias, Rio de Janeiro. 20 jun. 1898, apud ARAÚJO, 1976

JOE. CINEMATOGRAPHO. Gazeta de Notícias, Rio de Janeiro, p. 01.01 set. 1907; 13 set. 1907; 15 set. 1907 ; 19 set. 1907; 29 set. 1907; 12 abril 1908; 17 maio1908; 14 jun. 1908; 13 set. 1908.

O Paiz, 23 fev. 1907, apud SILVA, 2003 